\title{
Safeguarding the Impacts of Human Genome Editing
}

\author{
Khurshid Ahmad Tariq* \\ Department of Zoology, Islamia College of Science \& Commerce, India
}

Submission: June 08, 2018; Published: August 01, 2018

*Corresponding author: Khurshid Ahmad Tariq, Department of Zoology, Islamia College of Science \& Commerce, Srinagar, Kashmir, India; Email: drkatariq@gmail.com

\begin{abstract}
A genetic disorder is a rare congenital disease caused by certain abnormalities in the human genome. Their control, treatment and prevention is a big challenge. Various technologies and methods of human genome editing (genomic medicine, gene therapy, gene technology, and genetic engineering) have already advanced towards clinical trials in humans especially at the level of embryos. However, the bioethical issues in this context has invariably questioned its use and its implications on human societies now and in future. Fears of "neo-eugenic future" and "danger of genetic misuse" have been recognised and such a debate is in vogue. In this context, we can certainly ask few questions to ourselves that put us in the dilemma. Who are we to manipulate nature? However, if we can safely prevent severe genetic diseases and create healthy humans, why not manipulate the nature. Just like other human rights, humans have also rights at the level of genes and human genetic rights have also been recognised by the UNO. An immediate priority is, therefore, protecting and regulating the use of genetic information about individuals and safe guarding the long-term impact of genome technology on cultural and racial diversity. There is a tremendous scope that the medical professionals, academicians, scientists, genetic engineers, law-makers, religious and social leaders must work in cohort and address the issues involved in the practices of genetic technologies for reproductive, curative and research purposes.
\end{abstract}

Keywords: Bioethics, genetic diseases, genome editing, human genetic rights Genetic disorder; Bioethical; Nature; Humans; Racial diversity; Engineers; Law-makers; Huntington's disease; Sickle cell anaemia; Cystic fibrosis; Various metabolic disorders; Glycogen storage diseases; Planet; Medicine; Womb; Bubble boy disease; Diabetes; Egg; Drug resistance; Social scientists; Public policy

Abbreviations: SCGT: Somatic Cell Gene Therapy; GGT: Germ line Gene Therapy; PGID: Pre-Implantation Genetic Diagnosis; CRISPR: Clustered Regularly Interspaced Short Palindromic Repeats; RAAV: Recombinant Adeno-Associated Virus; IBC: Bioethics Committee; ABC: Assisting Bioethics Committees

\section{Introduction}

This paper reviews the promises, challenges and ethical implications of human genome editing. In the age of rapid technological advancements in biomedical science, genes (DNA) have achieved the prior importance. Identification of approximately 25000 to 30000 genes in the human genome and more than 4000 genetic disorders has created great benefits in diagnosis and treatment of diseases through the use of gene technology. Some of the important human genetic disorders responsible for mortality and severe morbidity are Huntington's disease, Sickle cell anaemia, cystic fibrosis, Duchenne muscular dystrophy, Haemophilia, Colour blindness, Patau syndrome, Down syndrome, Edwards syndrome, Cat cry syndrome, Werner's syndrome (progeria), Marfan syndrome, Klinefelter syndrome, Multifactorial disorders (Cancer), mitochondrial diseases, various metabolic disorders, glycogen storage diseases, etc. These diseases are either life threatening or debilitating and are a great challenge to human survival on this planet. The use of gene technology can be as simple as turning bad genes into good or healthy genes, or eliminating dead cells from the body, repairing damaged cells or treatments with stem cells.

The new technological interventions including nanotechnology which is now the key gene manipulation technique have even enabled the genetic engineers to develop anti-aging treatment or immortality so as to ultimately cure the cancer- the deadly disease. Even death will be optional because genetic engineers are trying to reverse the aging process of telomeres by promoting the lengthening of telomeres. Genetic technologies have created many interesting ethical issues which can affect the human societies now and, in the future, [1]. Some argue that moral concerns limit but do not prohibit the germ line genetic engineering.

The history of gene technology dates back to 1972 when Friedman and Roblin authored a paper in Science titled "gene therapy for human genetic diseases". Gene therapy either Somatic Cell Gene Therapy (SCGT) or Germ line Gene Therapy (GGT) is the therapeutic delivery of nucleic acid polymers 
(therapeutic gene) into patient's cells as drugs to treat genetic diseases (mutated genes) with multiple delivery techniques involving diverse vectors. The first gene therapy experiment was approved by the US FDA in 1990 when a patient was treated for ADA-SCID. Formally the first commercial gene therapy called as Gendicine was setup in China for the treatment of certain cancers. The delivery of healthcare in this context has brought along important social and scientific issues and posing questions to the very distinctiveness and survival of human beings.

\section{Significance of genomic medicine/gene therapy}

Right to health is a well-recognised fundamental right. As such, it cannot be denied that perfect health is only an imaginary and abstract condition in today's world. Therefore, the genome editing has evolved in due course of time to ensure the right to good health and quality life. Genome medicine or gene editing or genome editing or genetic engineering or gene therapy can simply be explained as the alteration of an organism's genetic or hereditary material (DNA) to eliminate undesirable characteristics or diseases, to produce desirable new ones or to treat the abnormality for a better health. It is either based on loss of function (functional forms of the genome are removed from the system), or gain of function (active, often mutant forms of the genome are introduced into the system) [2]. Tremendous breakthrough has been made in the field of gene editing technologies to treat the cases of genetic disorders, with the intension to increase the longevity of such patients and decrease the incidence of their transmission to next generations [3].

Stem cell research in this direction has already advanced towards clinical trials in humans especially at the level of embryo screening (reprogenetics) and manipulating with a step towards made to order babies (power to choose the traits in the babies as per the wish). Pre-Implantation Genetic Diagnosis (PIGD) or embryo profiling is another form of reprogenesis to screen the gametocytes or the initial embryo for evaluating the embryos at a certain risk of a genetic disorder to avoid unwanted pregnancy. Embryo transfer takes place after two to three days when the desired eggs are collected and fertilised under laboratory conditions. Or blastocysts are also transferred after around one week of artificial fertilization in the laboratory. A new technique called Metabolomics ensures that embryos with the best chance of implantation are selected and transferred into womb.

The gene editing is achieved in the lab using the tools called as engineered nucleases (restriction enzymes) or molecular scissors. There are a number of recognised gene editing techniques and methods, for example, CRISPR (Clustered Regularly Interspaced Short Palindromic Repeats), ZFNs (Zinc Finger Nucleases), RAAV (Recombinant Adeno-Associated Virus), Transposons (jumping genes), Cell line engineering in human cancer cells and mammalian models (knockout mice and rats).

Today genetic engineering is used in fighting problems such as cystic fibrosis, cancer, diabetes and several other deadly diseases like the "bubble boy" disease. This is a clear indication that genetic engineering has the potential to improve the quality of life, allow for longer life span, helping cure illness and diseases in unborn (genetic screening of foetus) children $[4,5]$. While genome editing applied to human pre-implantation embryos could completely eradicate genetic diseases, scientists have warned that it should be treated with caution and could be used for non-therapeutic modifications [6]. Since germ line modification causes genetic changes to the embryos, changes that are heritable, this technique can have unpredictable effects to the future generations. However, this procedure will open the door to the loss of human diversity and eugenics [7].

\section{Promises, challenges and issues of genome editing technologies}

Promises: The genome editing can be successfully employed for the generation of "non-viable" embryos (triponuclear zygotes-can't create foetus or new individuals), that can be very useful in research to understand the mechanism of various genetic disorders and their prevention [8]. Gene editing if used for the production of human medicine can't raise any ethical concerns thus can be of great significance in preventive sciences. The gene editing if limited to modification of somatic cell DNA [6] can really help in the gene therapy of so many genetic diseases in adults or children with no chances of transfer to next generations. This field is of great promise and can really prove a boon in the field of genome technology. Creation of isogenic cell lines and animal models by using various methods and techniques of gene technology for the study of human diseases is similarly of quite great significance in fighting problems with diseases like cystic fibrosis, cancer, diabetes, bubble boy disease (severe combined immunodeficiency disease) [9].

Challenges: Surrogacy and human egg trade (egg trafficking) from poor countries to rich is one of the big challenges of modern day technology era and needs proper legislation and regulation. The use of genome editing at the level of embryo (reprogenetics) can result in the production of unnecessary and undue heritable genetic changes to the embryos that can have unpredictable effects to the future generations. This is the second biggest challenge faced today. The indiscriminate use of genome editing in human population will open the door to the loss of human diversity. Similarly, new organisms created due to gene editing can be agents of ecological imbalance, source of new infectious epidemic agents and the complicated problems with emergence of antibiotic resistance/drug resistance.

Issues: The evolution of bioethical issues question the use of genome editing \& its implications on human societies and survival. There is a development of fear of "neo-eugenic future" and "danger of genetic misuse" due to genome technology use. Nature creates human as per the natural laws and as per the fitness in the environment as per the rules of the natural selection. Through the use of gene technology, genetically engineered humans created will possess certain desired but 
unnatural traits or characters. This puts us in the dilemma, who are we to manipulate nature and natural laws? However, there is one great issue about which the consensus is yet to develop, that is-if we can safely prevent the occurrence and development of genetic disorders and create healthy humans, why not to manipulate nature.

\section{Role of genetic clinics (genetic counselling)}

A genetic disorder is especially a very rare and heritable congenital disease caused by certain defects, abnormalities and mutation in the human genome. These diseases may be somatic or germ line in nature and result either from a change in a single gene (mutation) or a multiple of genes (chromosomal abnormalities). Some other genetic defects result due to epigenetic alterations and in such situation are not heritable. Genetic counselling plays an important role in the management, control and prevention of genetic diseases. The genetic counselling and eugenics together envision the improvement of humankind with enhancement of both physical and mental capabilities, however, it is open to challenges and ethics. The role of genetic counsellor is to inform and advise patients or their relatives at risk of a certain heritable genetic disorder, of the consequences and the nature of the disease. Further, the information about the probability of developing and transmitting a particular disease and the options open to them in management and family planning is also provided by a genetic counsellor. For example, the timely counselling about the consanguineous marriages and its influence on the incidence of genetic disorders is quite useful to prevent the prevalence of genetic disorders among the families.

\section{Ethical concerns of gene editing}

Ethics is defined as the "set of principles or beliefs that govern people's views of right or wrong, good or bad, fair or unfair, just or unjust" and is, therefore, a key determinant of professional conduct in biomedical science. All the people associated with biomedical engineering are expected to adhere to the code of ethical conduct. However, its importance, there has been a lack of research on the ethical concerns and challenges faced by the geneticists and the other associated staff. So there remains a question of what to do and what not to do within the domain of use of genome editing for correcting genetic disorders, for example, the use of "non-viable" embryos in research obtained from fertility clinics do not result in a live birth because they are fertilized by two sperms giving rise to trip nuclear zygotes [8], so can be considered for practical applications of genome editing. Similarly, the production of human medicine through this technology has also been encouraged.

Human egg trade (egg trafficking) is on the increasing trend from the poor countries to the rich ones, and it is a challenge. The genome editing technologies currently in various clinical development stages are limited to modification of genetic material of somatic cells [6], and it looks promising, however only after the risk assessment is carried out. Gene technology has provided researchers with the ability to manipulate virtually any genomic sequence, enabling the facile creation of isogenic cell lines and animal models for the study of human diseases, and promoting new possibilities for gene therapy [9]. However, the evolution of bioethical issues has questioned its use and the implications of such a powerful technology on human societies [10]. There is a fear of "neo-eugenic future" and "danger of genetic misuse" and such a debate is in vogue in the world. In this direction we can certainly ask few questions to ourselves that puts us in the dilemma. Who are we to manipulate nature? However, for all those who suffer from genetic diseases the answer is not so simple; if we can safely prevent severe genetic diseases and create healthy humans, why not manipulate nature $[11,12]$. New organisms created by genetic engineering could present an ecological imbalance, threat of new infectious epidemic agents and problems with antibiotic resistance. Looking at the fact that genetic engineering employs viral vector genes which may replace the important human genes, instead of mutated genes, therefore, there will be a reduction in genetic diversity in human, which will create susceptibility towards diseases.

Playing nature and natural laws has become a strong argument against genome editing. Several issues have already been raised about the use of this technology in human. For instance, ongoing advances make it increasingly likely that scientists will someday be able to genetically engineer humans to possess certain desired traits. Although such questions rarely have clear and definite answers, the expertise and research of bioethicists, sociologists, anthropologists, and other social scientists can inform us about how different individuals, cultures, and religions view the ethical boundaries for the uses of genomics. Moreover, such insights have assisted in the development of several guidelines and policies already in vogue. Therefore, further testing and research will be required to educate society on the pros and cons of genetic engineering. There is no doubt that this technology will continue to present intriguing and difficult challenges for scientists and ethicists, and education and meaningful, respectful discourse are just the starting point of what is required to tackle such complex ethical issues.

\section{Human rights legislation, genetics and safeguarding of bioethical issues}

Just like other human rights, humans have also rights at the level of genes and human genetic rights have also been recognised by the UNO in 1998. An immediate priority is, therefore, protecting and regulating the use of genetic information about particular individuals and safe guarding the long-term impact of genetic technology on human genetic rights, cultural, racial and ethnic diversity.

Since the inception of various declarations, unions, committees at international and national level, diversified policies guidelines have been formulated for practicing human 
genome medicine and to address the ethical concerns of genome editing technologies. A growing number of scientific practices have extended beyond national borders and the necessity of setting universal ethical guidelines covering all issues raised in the field of bioethics. Some of the important bodies in this context are: The Universal Declaration on the Human Genome and Human Rights(1998); Universal Declaration on Bioethics and Human Rights; UNESCO Universal declaration on the human genome and human rights (1997 and endorsed by the UNGA in 1998); The international declaration on human genetic data adopted (2003; International Bioethics Committee (IBC), 1993); Intergovernmental Bioethics Committee (IGBC, 1998 of 36 member states);Assisting Bioethics Committees (ABC): The Universal Declaration on Bioethics and Human Rights advocated the establishment of independent, multidisciplinary and pluralist ethics committees at national, regional, local or institutional levels assisted by UNESCO ABC project; National Bioethics Committees at various levels of government involved in policyadvice, public debateandeducation of various countries; Council of Europe (47-members);European Union(27-members); African Union; Group of Eight (G-8-Canada, France, Germany, Italy, Japan, Russia, the UK, and the US); Ethics committee of India: The first official guidelines for the formation of ECs were issued by the Indian Council for Medical Research in February 1980.

The significant progress being made in clinical development of approaches to cure deleterious diseases should not be impeded by concerns regarding the ethical implications of germline editing [12]. There is a tremendous scope that the medical professionals, genetic engineers, law-makers, general public, academia, scientists, bioethicists, public policy and legal experts, religious and social leaders must work in cohort and address these issues involved in the practices of genetic technologies for reproductive, curative and research purposes for the betterment of human race.

\section{Conclusion}

The genetic disorders along with the evolution of ethical implications of genome editing are a big challenge to human survival. The significant progress made in clinical development to cure and treat a variety of genetic diseases in human beings can't be impeded by merely the ethical implications, however a balance is to be setup somewhere, what to do and what not to do vis-à-vis the use of gene technology for correcting the genetic disorders. Medical professionals, genetic engineers, general public, academia, scientists, bioethicists, policy makers, lawmakers, legal experts, religious and social leaders must work in cohort to address the bioethical issues of genome editing for the betterment of human race and good health.

\section{References}

1. Ardekani AM (2009) Gene technologies and ethics. J Med Ethics Hist Med 2: 11.

2. Patra SAA (2015) Effects of Genetic Engineering-The Ethical and Social Implications. Annals of Clinical and Laboratory Research 3: 5.

3. Otieno MO (2015) CRISPR-Cas9 Human Genome Editing: Challenges, Ethical Concerns and Implications. Journal of Clinical Research \& Bioethics 6: 253.

4. Fischer A, Hacein-Bey S, Cavazzana-Calvo M (2002) Gene therapy of severe combined immunodeficiencies. Nat Rev Immunol 2(8): 615621.

5. Cavazzana-Calvo M, Chantal L, Hacein-Bey S, Fischer A (2005) Gene therapy for severe combined immunodeficiency. Annual review of Medicine 56: 585-602

6. Lanphier E, Urnov F, Haeker SE, Werner M (2015) Don't edit the human germ line. Nature 519(7544): 410-411.

7. Yang A (2015) Thinking towards the future of CRISPR/Cas9. Brevia 8.

8. Liang P, Xu Y, Zhang X, Ding C, Rui Huang, et al. (2015) CRISPR/Cas9mediated gene editing in human tripronuclear zygotes. Protein \&Cell 6(5): 363-372.

9. Gaj T, Sirk SJ, Shui S, Liu J (2018) Genome-Editing Technologies: Principles and Applications. Cold Spring Harbor Perspectives in Biology 10(7)

10. D’Halluin K, Ruiter R (2013) Directed genome engineering for genome optimization. Int J Dev Biol 57(6-8): 621-627.

11. Sivapatham R (2015) Ethical implications of human genetic engineering. The Science of Aging.

12. Cyranoski D, Reardon S (2015) Chinese scientists genetically modify human embryos. Nature News.

\section{Your next submission with Juniper Publishers will reach you the below assets}

- Quality Editorial service

- Swift Peer Review

- Reprints availability

- E-prints Service

- Manuscript Podcast for convenient understanding

- Global attainment for your research

- Manuscript accessibility in different formats

( Pdf, E-pub, Full Text, Audio)

- Unceasing customer service

Track the below URL for one-step submission https://juniperpublishers.com/online-submission.php 